\title{
SISTEMA DE MOBILIDADE PARA EQUOTERAPIA: PROCESSO DE ELABORAÇÃO DE UM MODELO EM ESCALA REAL PARA VALIDAÇÃO DE ALTERNATIVA DE EQUIPAMENTO
}

Paula Conceição Rocha de Oliveira (ra93134@uem.br) - Universidade Estadual de Maringá, UEM.

Guilherme Neto Ferrari (a96030@uem.br) - Universidade Estadual de Maringá, UEM.

Maria de Lourdes Santiago Luz (ํlsluz@uem.br) - Universidade Estadual de Maringá, UEM.

Bruno Montanari Razza (bmrazza@uem.br) - Universidade Estadual de Maringá, UEM.

\section{RESUMO}

Uma das atividades de maior importância no desenvolvimento de um produto é a validação das informações, requisitos e decisões tomadas para sua construção junto aos interessados no projeto, de forma a se ter certeza de que o que está sendo produzido é, de fato, o que atende às necessidades do usuário. O produto em estudo é um sistema de mobilidade para praticantes de equoterapia, desenvolvido de forma a minimizar os esforços biomecânicos dos profissionais de equoterapia mas sem comprometer a segurança do praticante, por isso, a validação das conformidades e necessidades do equipamento é indispensável. Dessa forma, para validar a alternativa de solução selecionada, verificando questões estruturais, dimensionais e de segurança do produto, foi desenvolvido um modelo em escala real a ser apresentado aos usuários. A proposta deste estudo é apresentar as informações, questões e etapas essenciais para o desenvolvimento deste modelo, discutindo sua concepção e também os resultados obtidos. Com o modelo, foi possível notar algumas adversidades não percebidas com o desenho 3D, como o superdimensionamento de algumas peças, algumas dificuldades de movimentação de peças articuladas que conflitavam com outras, entre outros aspectos, contribuindo para um aprimoramento do produto final.

Palavras chave: protótipo; modelo em escala real; equoterapia; desenvolvimento de produto; testes com usuário. 


\section{INTRODUÇÃO}

Segundo a ANDE (2019), a equoterapia trabalha com o cavalo em um método terapêutico que busca desenvolver a esfera psicossocial de pessoas com deficiência e necessidades especiais. A prática envolve três agentes principais que trabalham de forma harmônica: o profissional de equoterapia, podendo ser terapeutas ocupacionais, fonoaudiólogos, fisioterapeutas e pedagogos (LÉVEILLÉ; ROCHETTE; MAINVILLE, 2017); o praticante, cuja faixa etária vai desde crianças até idosos, abrangendo pessoas com diferentes condições e necessidades que afetam funções motoras, cognitivas, emocionais e de fala (LESSICK et al., 2004); e o cavalo, cujos movimentos tridimensionais funcionam como uma ferramenta terapêutica, e trabalha como um "coterapeuta" nas atividades (PAVÃO, 2015).

Por meio de estudos ergonômicos em um centro de equoterapia da cidade de Maringá, notou-se um elevado esforço biomecânico exercido pelos profissionais de equoterapia, indicando altos riscos ocupacionais e desconfortos em suas atividades, principalmente no processo de transportar o praticante até o cavalo, tornando evidente a necessidade de uma intervenção que reduza esses riscos (LUZ; BOARETTO; RODRIGUES, 2017).

Collins et al. (2004) afirmam que a utilização de equipamentos mecânicos de elevação trazem resultados significativos na redução da ocorrência de lesões, assim como dos custos associados, como dias perdidos de trabalho. Tendo isso em vista, uma equipe multidisciplinar foi estabelecida para o desenvolvimento de um sistema de mobilidade capaz de sanar o problema ergonômico visualizado por Luz, Boaretto e Rodrigues (2017) e Boaretto et al. (2018) no centro de equoterapia de Maringá.

Ao final da etapa conceitual do sistema de mobilidade, iniciou-se a etapa de detalhamento, na qual a geração e refinamento de alternativas foram realizados, conforme sugere Pahl et al. (2007), assim como o detalhamento e especificações dos componentes, conforme citam Rozenfeld et al. (2006). É sugerido por Baxter (2011) que se dê início à construção e testes de modelos e protótipos e, segundo Lobach (2001), realizar a construção da solução para o problema e sua avaliação final, por meio de projeto mecânico e estrutural, e por modelos, desenhos técnicos e representações.

Segundo Pazmino (2013), nas etapas de análise, criatividade e detalhamento, recomenda-se utilizar de metodologias e ferramentas que avaliem as atividades realizadas até o momento, auxiliando na seleção das melhores escolhas para o projeto e geração de novas ideias, considerando todos os envolvidos. 
Portanto, buscando avaliar a situação do desenvolvimento do equipamento, foi aplicada a metodologia de grupo focal com os interessados no projeto, ou seja, os profissionais do centro de equoterapia, no qual foram exibidas as atividades realizadas no projeto e decisões tomadas na definição das funcionalidades e estrutura do produto. Neste momento, foi verificada a necessidade de desenvolver um modelo em escala real para avaliar as dimensões do equipamento quando montado no ambiente de trabalho do centro, assim como questões estruturais do equipamento e seu funcionamento.

Este estudo trata do desenvolvimento deste modelo em escala real, discutindo sua importância e a metodologia para a sua concepção. A opinião dos usuários é de suma importância para este projeto e se dá presente em todas suas etapas, já tendo sido coletada na elaboração dos requisitos por meio de visitas de campo, na apresentação de soluções por meio do grupo focal e, finalmente, por meio da elaboração do modelo em escala real. Esse é o momento de confirmar que a coleta de requisitos foi correta e que as necessidades elencadas estão sendo cumpridas e as expectativas serão atendidas. Por fim, a discussão traz alguns pontos notados devido ao desenvolvimento do modelo, pontos que não foram e nem seriam percebidos com apenas o modelo CAD (Computer Aided Design) ou desenhos 2D.

\section{REVISÃO TEÓRICA}

Por trás de produtos de sucesso existem histórias de tentativas e erros, já que a transformação de uma ideia em algo material envolve mais do que desenhos (PALHAIS, 2015). Por isso, a elaboração de protótipos no desenvolvimento de produtos é de suma importância na validação de ideias. Quanto mais rápido for possível materializar uma ideia, mais rápido ela poderá ser avaliada e refinada (BROWN, 2009).

Uma abordagem do design moderno é investigar como as pessoas interagem com os produtos, interface ou serviços, utilizando suposições de comportamentos e validando-as ou eliminando-as por meio de protótipos e experimentação (PALHAIS, 2015). Sendo assim, os protótipos são comumente utilizados com o propósito de testar estes aspectos de interação.

A palavra prototipagem define um grupo de técnicas de fabricação no processo de construção de modelos para análises que servirão de base para um produto final, sendo o protótipo a materialização de uma ideia, com intuito de simular seus aspectos (PALHAIS, 2015). Os modelos físicos possibilitam análises mais fáceis pelo usuário se comparados àqueles 
desenvolvidos em softwares de simulação, gerando interação com as peças e facilitando a comunicação entre projetista e usuário (PALHAIS, 2015).

Quando não existem aspectos específicos do usuário, o protótipo também pode ser testado pela equipe de desenvolvimento, permitindo a exploração de várias ideias em paralelo (BROWN, 2009). Isso permite a análise inicial de encaixes e dimensionamento de peças pela equipe de projeto, fornecendo uma visão técnica e encarregando para o usuário apenas testes relevantes para questões de interação.

Segundo Palhais (2015), dimensões físicas e as proporções tangíveis ilustram de forma clara o que desenhos bidimensionais não conseguem, o uso do modelo em escala real às vezes se torna mais eficaz na transmissão de ideias do que imagens, já que muitas vezes o usuário não consegue visualizar o projeto apenas por meio de representações gráficas (MUNARI, 2015). Percebe-se, assim, a importância de transmitir a ideia para o usuário por diversos meios, com o objetivo de facilitar e melhorar a sua compreensão acerca do projeto.

Os modelos podem ter várias funções, como demonstrações práticas, teste de materiais ou apresentação de algum tipo de funcionamento do equipamento e disposição de objetos, podendo ser elaborados por meio de papel ou até materiais mais sofisticados (MUNARI, 2015). O protótipo deve ser encarado como um processo evolutivo, sendo avaliado e refinado continuamente até se atingir o produto final (PALHAIS, 2015). Desse modo, vê-se a importância de fazer uma análise crítica de todos os aspectos possíveis nos modelos e protótipos desenvolvidos.

Palhais (2015) recomenda, para testes com protótipos, que o modelo deve ser claro sobre o teste e as tarefas a serem realizadas com ele; deve-se observar e documentar todas as interações; obter aprovação ética antes de realizar qualquer tipo de teste e nunca utilizar modelos que gerem perigo ou constrangimento ao usuário. Por isso, é necessário planejar os procedimentos, visando informar claramente ao usuário sobre seu papel no processo e estruturar a análise, de forma a evitar possíveis esquecimentos durante o teste.

\section{METODOLOGIA}

Ao final da etapa conceitual, viu-se a necessidade de coletar percepções dos usuários acerca da alternativa final que estava em desenvolvimento, para isso realizou-se um grupo focal (Figura 1) com os profissionais do centro de equoterapia, onde foi possível apresentar as pesquisas que foram feitas pela equipe sobre o assunto; os requisitos que foram gerados e de 
onde foram retirados; os detalhamentos da alternativa final - seu funcionamento, armazenagem, manutenção - por meio de representação gráfica de modelo CAD.

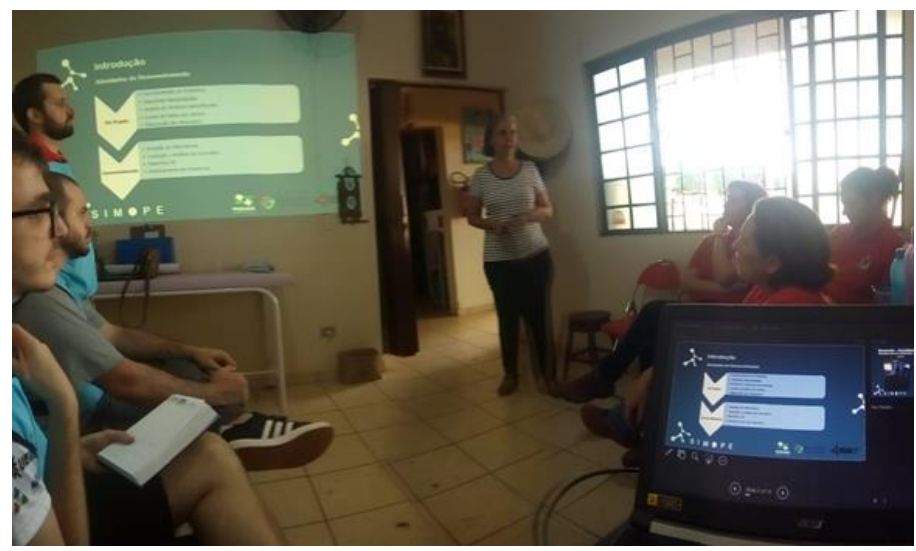

FIGURA 1 - Realização do grupo focal com as profissionais do centro de equoterapia. Fonte: Autores (2019).

Os resultados do grupo focal serviram de direcionamento para elaborar o primeiro modelo em escala real, no qual foram utilizadas as percepções e comentários dos profissionais do centro. Dentre as principais preocupações demonstradas pelos participantes do grupo focal, destaca-se a necessidade de testar a percepção do cavalo em relação ao protótipo, já que a presença de um equipamento novo pode gerar reações inesperadas ou até mesmo perigosas para os envolvidos na prática terapêutica. Outras preocupações levantadas foram: a movimentação do equipamento e de suas peças, a proporção em relação ao local de uso e armazenagem e as etapas de utilização do equipamento.

Para guiar o processo de prototipagem, foi realizada uma estratégia de prototipagem exemplificada na Figura 2, definida por Brown (2009) como um conjunto de decisões e opiniões que ditam as ações que serão tomadas para a realização eficaz do protótipo. Sendo assim, houve o planejamento do desenvolvimento do modelo em escala real, utilizando o referencial teórico coletado, as percepções e comentários do grupo focal e os limites e necessidades do projeto.
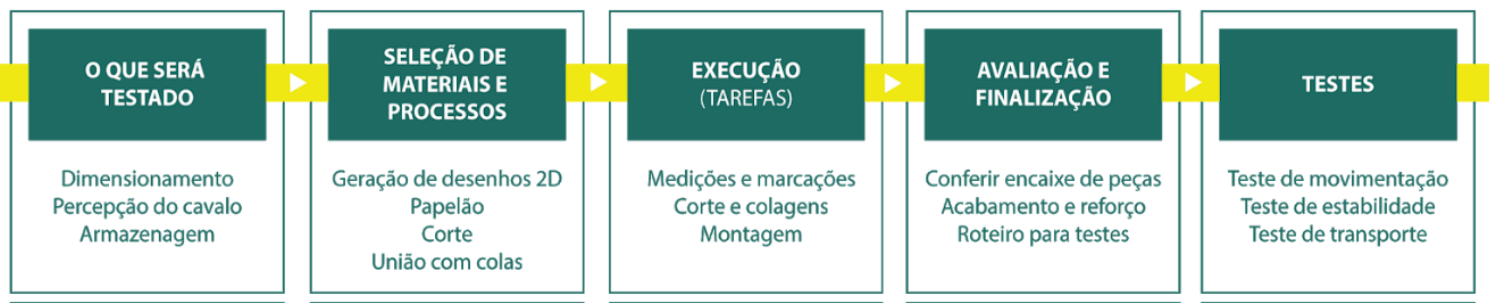

FIGURA 2 - Planejamento do desenvolvimento do modelo. Fonte: Autores (2019). 
Primeiramente foi utilizado o modelo CAD apresentado durante o grupo focal para gerar desenhos técnicos das peças e conjuntos, como mostrado na Figura 3, visando utilizar dimensões e geometrias corretas em relação ao que foi definido e apresentado aos usuários. Esses desenhos serviram para auxiliar no processo de seleção de materiais e processos do modelo que foi elaborado.

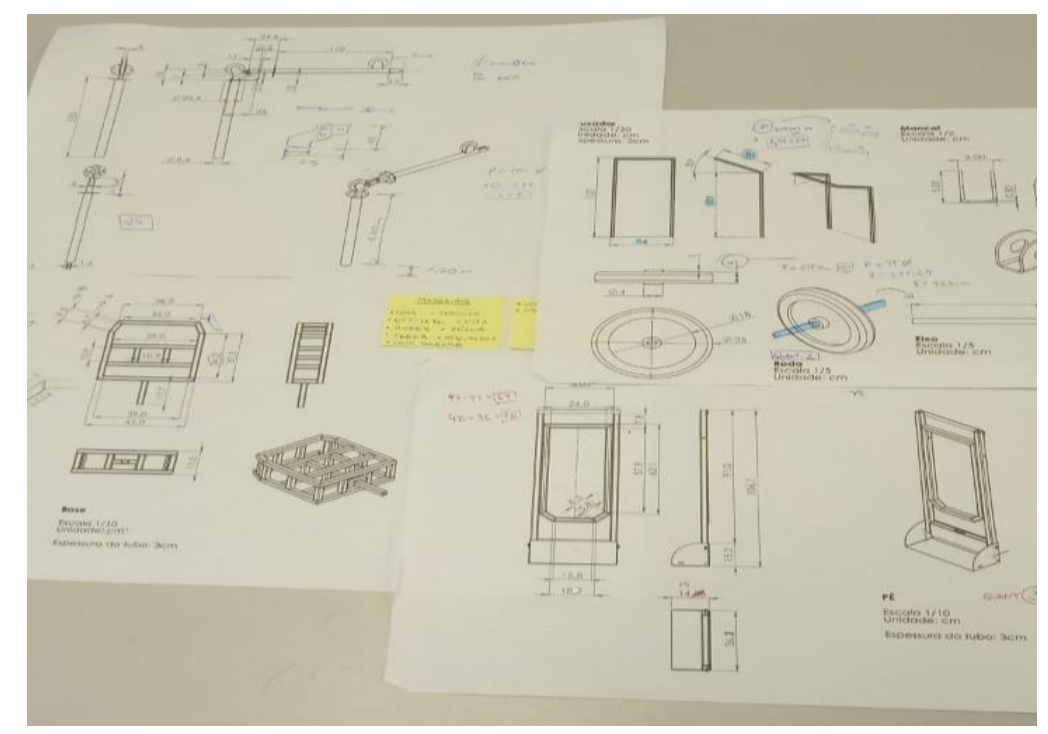

FIGURA 3 - Desenhos técnicos do modelo CAD. Fonte: Autores (2019).

Para seleção dos materiais levou-se em consideração que, para manter a dinâmica do projeto, o primeiro modelo deveria ser de baixo custo, rápida execução, mesmo que seja rude, mas que permita testar o necessário, podendo ser configurado com materiais de baixa fidelidade, como sugerido por Palhais (2015).

Tomando como base que a estrutura do modelo CAD foi elaborada em chapas e tubos quadrados metálicos, optou-se por utilizar chapas de papelão rígido para simular as paredes metálicas, considerando que avaliações relacionadas à resistência do material final serão feitas em software especializado. Portanto, fez-se a escolha do papelão pelo aproveitamento de caixas descartadas que facilitam a obtenção de material, também pela fácil união e corte que ele proporciona, e por fim foi considerado o seu descarte posterior, atendendo requisitos de sustentabilidade. Foi feita uma coleta de papelão de vários tamanhos, formatos, rigidez, como mostrado na Figura 4. 


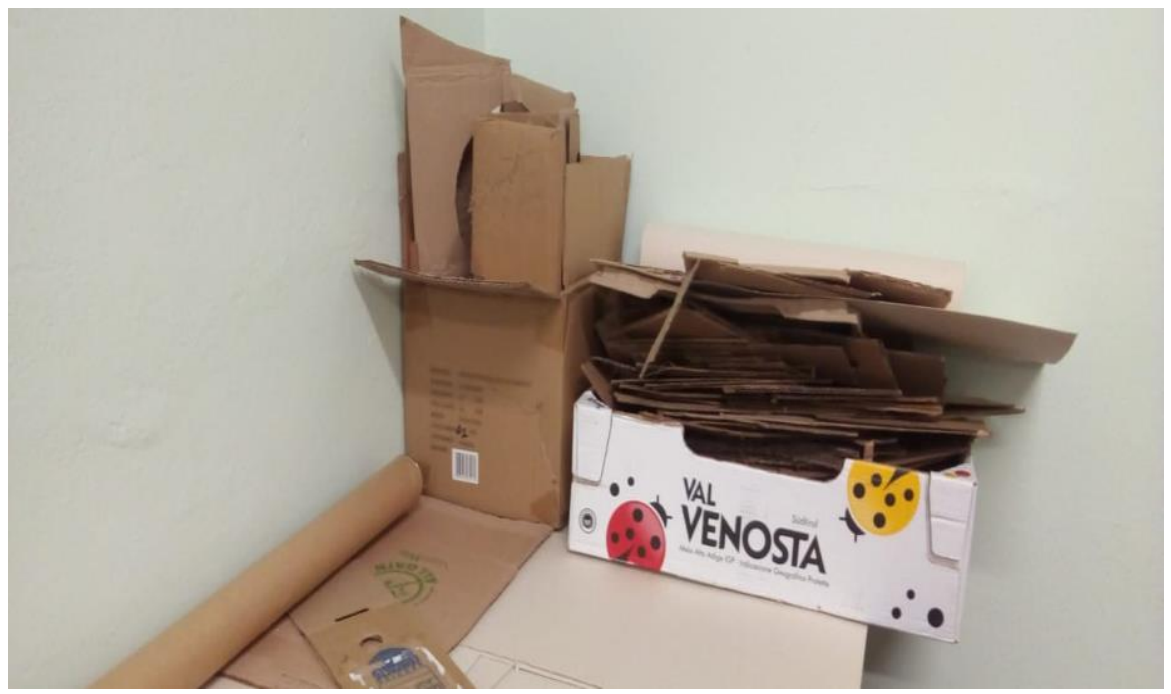

FIGURA 4 - Caixas de papelão utilizadas como material para o desenvolvimento do modelo. Fonte: Autores (2019).

Considerando que as dimensões máximas do modelo chegam quase a 3 metros, a divisão das tarefas foi feita entre dois integrantes do grupo de projeto, permitindo a montagem de peças e conjuntos maiores que, com apenas uma pessoa, seriam inviáveis. A participação de duas pessoas também auxiliou na conferência de medidas e marcações no papelão, buscando evitar erros de dimensionamento e simetria (Figura 5).
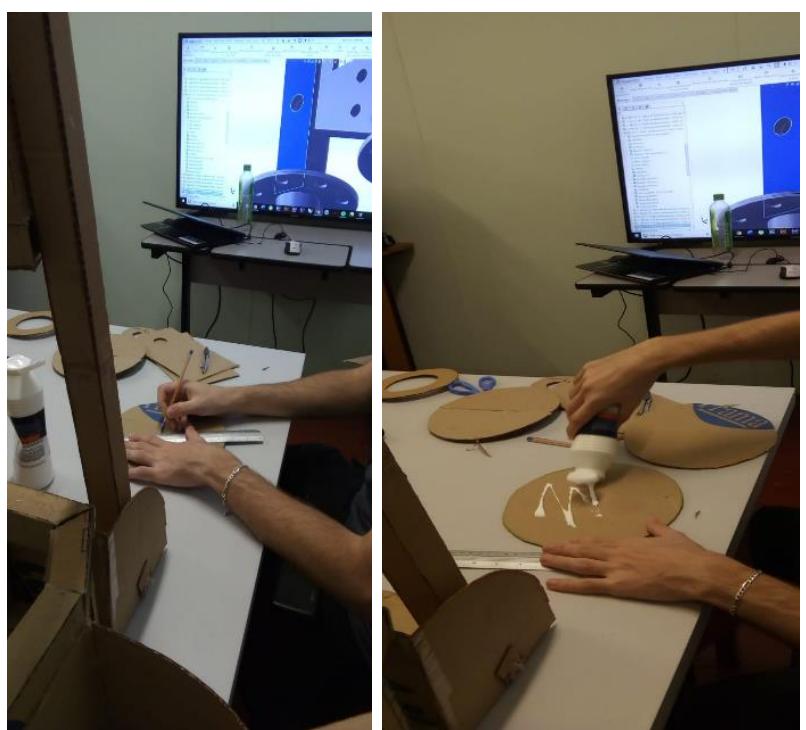

FIGURA 5 - Processo de medição, marcação, cortes do material e colagem. Fonte: Autores (2019). 
Dividiu-se as etapas de corte e de colagem por peça, em que cada peça teve sua elaboração e conferência antes de outra peça ser iniciada. Essa estratégia possibilitou a avaliação das partes individualmente, como exemplificado na Figura 6, diminuindo o risco de erro ao final da montagem.

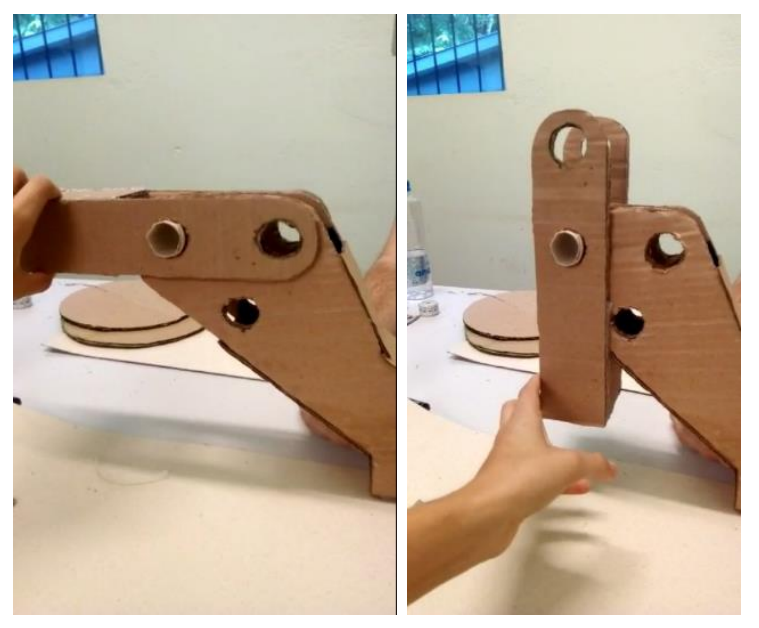

FIGURA 6 - Elaboração e conferência de peças. Fonte: Autores (2019).

A etapa seguinte foi a de montagem e união das peças. Para isso, utilizou-se desenhos técnicos do modelo CAD como referência das estruturas montadas. As peças fixas foram unidas com cola branca e cola quente e as peças articuladas ou com eixos foram unidas por meio de pinos ou palitos, conforme ilustrado na Figura 7. Essa etapa exigiu o trabalho em equipe, para que as peças maiores pudessem ser manipuladas.

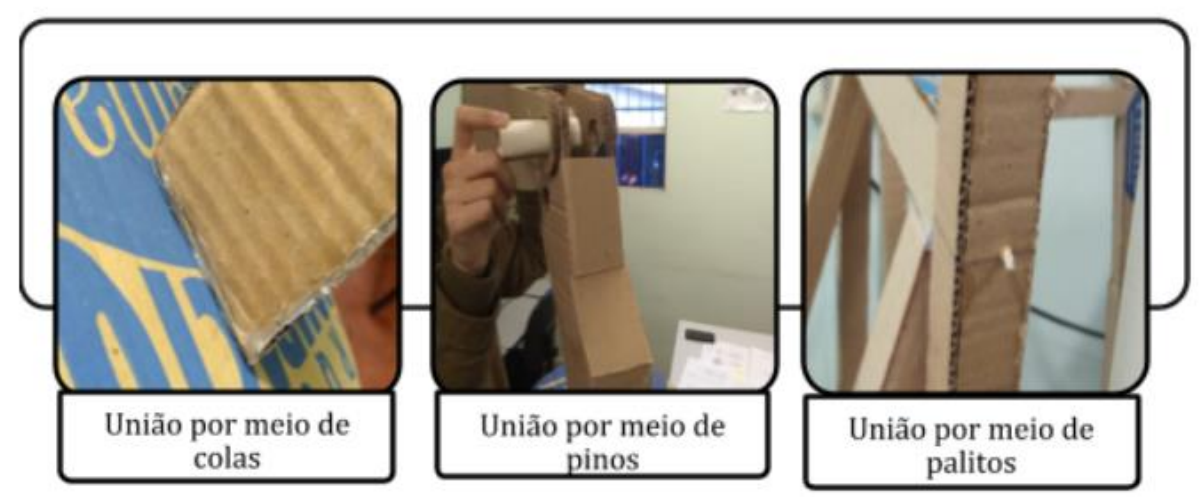

FIGURA 7 - Alternativas para fixação das peças por cola, por eixo, por pino. Fonte: Autores (2019).

Em sequência foi a fase de conferência do modelo como conjunto, onde as peças foram avaliadas em um contexto macro, com objetivo de verificar a estabilidade de seus encaixes e 
fluidez de suas movimentações. Dessa forma, foram necessários alguns reforços estruturais e acabamentos de superfície para finalizar o modelo.

Por fim, com o modelo pronto para utilização, foi iniciado o processo de planejamento do teste no centro de Equoterapia, contemplando o que precisava ser testado e como seria realizado esse processo. Foi elaborado um termo de consentimento livre e esclarecido, visando coletar autorizações dos participantes. Também houve uma preocupação em detalhar os procedimentos tanto para a equipe de aplicadores, quanto para os participantes.

O local de aplicação deve ser o centro de equoterapia parceiro do projeto, todo procedimentos de teste deve ser filmado e gravado para posteriores análises. O primeiro momento do teste foi planejado para ser uma exposição do procedimento para os usuários, destacando a importância da participação deles no desenvolvimento do equipamento e como seria o processo de teste do modelo. Para isso, elaborou-se um texto padrão inicial de apresentação onde a equipe do projeto deverá comunicar e tirar as possíveis dúvidas. Foram listados para controle interno alguns aspectos que devem ser analisados pela equipe de aplicação de teste, como as expressões faciais dos usuários durante o teste.

Após todas as explicações iniciais, devem ser expostas as etapas práticas, onde haverá o contato com o equipamento e a verificação de alguns aspectos de interação. Também percebeu-se a necessidade de elaborar perguntas pré-teste para coletar as expectativas dos usuários antes do primeiro contato com o modelo. Da mesma forma, foram realizados questionamentos durante e após a realização do teste.

\section{RESULTADOS E DISCUSSÃO}

Como resultado da elaboração do modelo em escala real, foi possível elencar aspectos que deveriam ser melhorados e refinados no protótipo final, dentre eles: questões estruturais, dimensionais, de funcionamento e de forma.

Um dos problemas na construção do modelo foi a utilização do papelão para superfícies cilíndricas. Por conta da geometria das camadas do papelão, as curvaturas apresentavam dobras, como ilustrado na esquerda da Figura 8, não formando cilindros corretos. Por esse motivo, optou-se pela troca de material, em que viu-se o papel paraná como uma solução mais adequada, como ilustrado na direita da Figura 8. Em contrapartida, o papel paraná tem propriedades diferentes do papelão, gerando uma divergência de resistência e estética, mas sem afetar o conjunto do equipamento. 

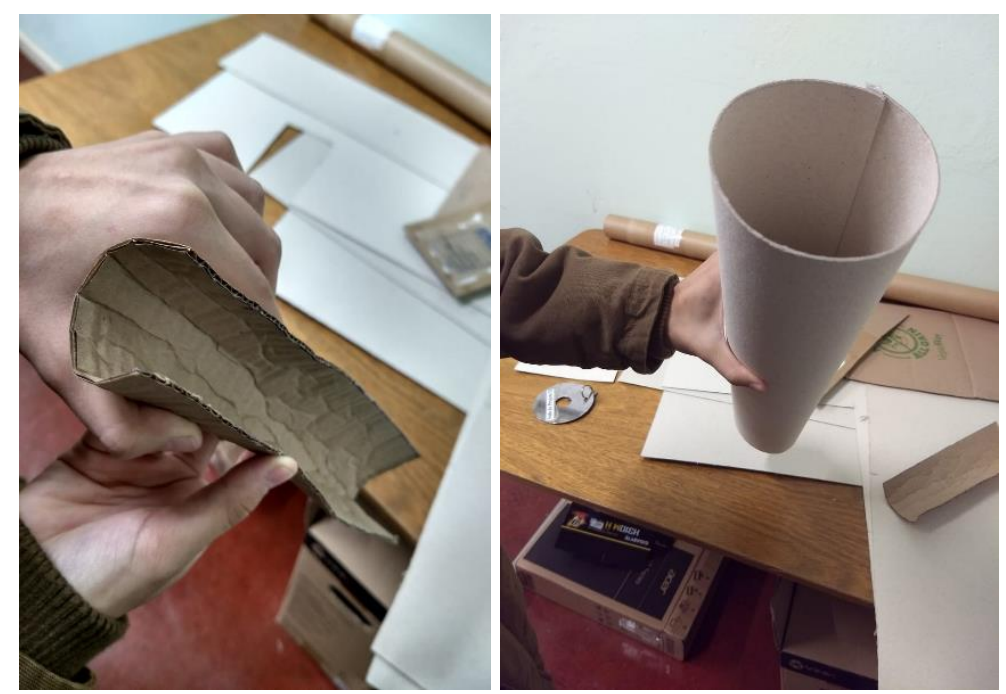

FIGURA 8 - Comparação entre a utilização de papelão e papel paraná para estrutura cilíndrica. Fonte: Autores (2019).

Nas questões estruturais foi percebido que algumas peças estavam conflitando com outras no momento do uso, dificultando o manuseio do equipamento, o que irá refletir em algumas mudanças de posicionamento.

Também houve uma percepção de super dimensionamento em relação a proporção humana, entretanto, essa percepção só será confirmada ou eliminada após a comparação do equipamento no local de destino com o local em que foi montado.

Houveram considerações em relação a uma peça de auxílio à movimentação e transporte do equipamento, o puxador, em que notou-se a divergência ergonômica do dimensionamento, ou seja, percebeu-se que o tamanho definido inicialmente estava inadequado e causava problemas ergonômicos, como mostrado à esquerda da Figura 9, uma vez que para realizar a pega o usuário precisa realizar posturas e movimentos desconfortáveis. Esse fato exige que essa peça sofra alterações no projeto do protótipo final tanto no seu tamanho como na sua forma, buscando melhorar a sua usabilidade. 

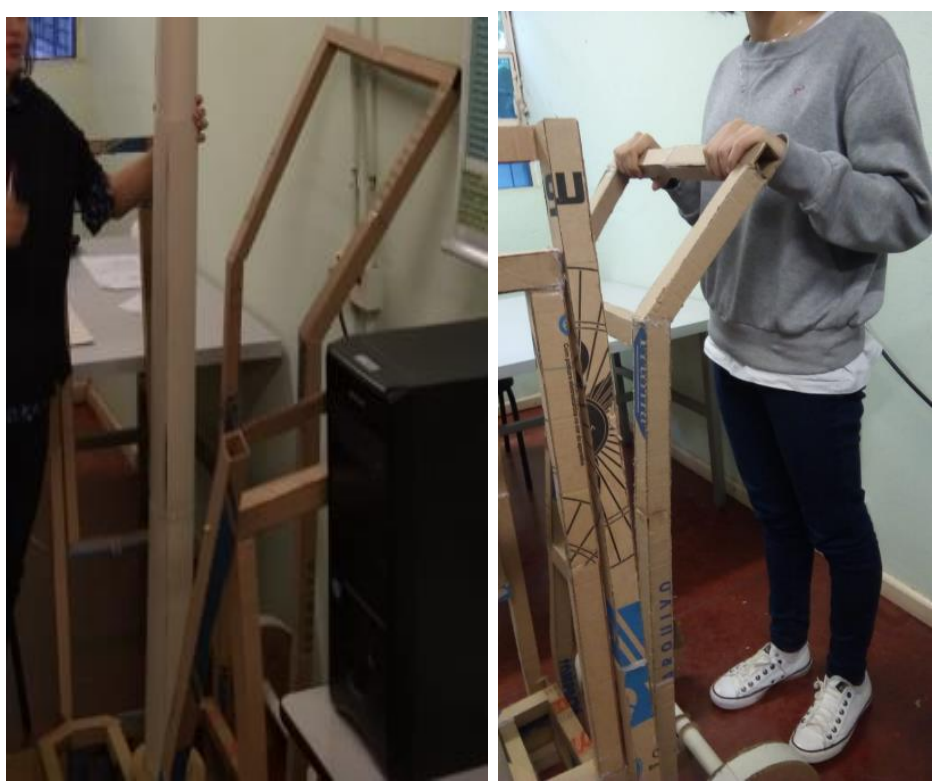

FIGURA 9 - Modificação da altura da pega entre o dimensionamento inicial do puxador e após a verificação de superdimensionamento. Fonte: Autores (2019).

Outra questão pendente foram os sistemas de travamento, por conta da complexidade de sistemas de molas e travas, não sendo possível simular no modelo físico igual ao que foi modelado no software CAD como apresentado na Figura 10 e, consequentemente, não houve a realização de testes desses sistemas. A solução foi improvisar com o material disponível, simulando, de forma simplificada, o funcionamento da trava, conforme exposto na Figura 11. Entretanto, percebeu-se a necessidade de transmitir aos usuários como será esse funcionamento, visando deixar-los mais seguros em relação ao protótipo final. Por isso, foi exemplificada de forma gráfica como seria o seu funcionamento.

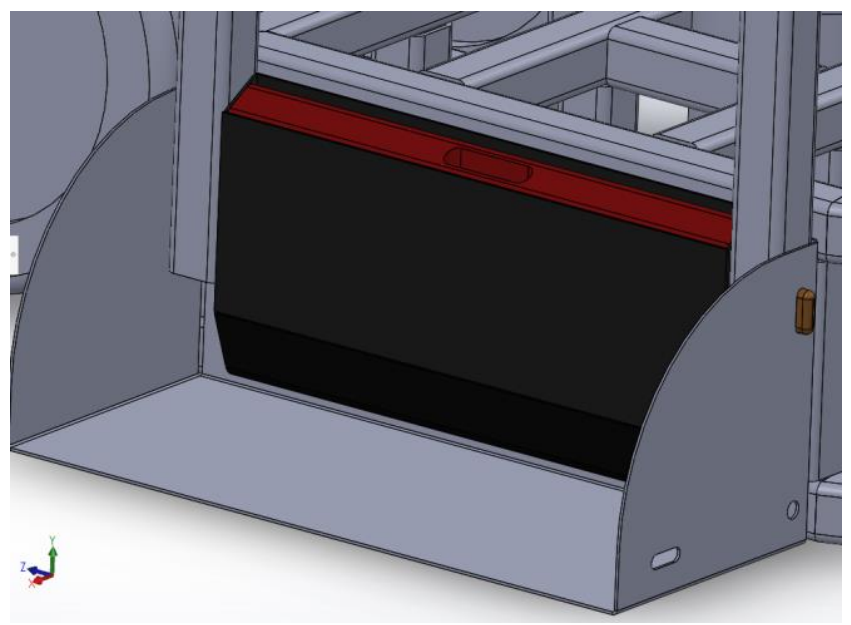


FIGURA 10 - Modelo CAD da trava. Fonte: Autores (2019).
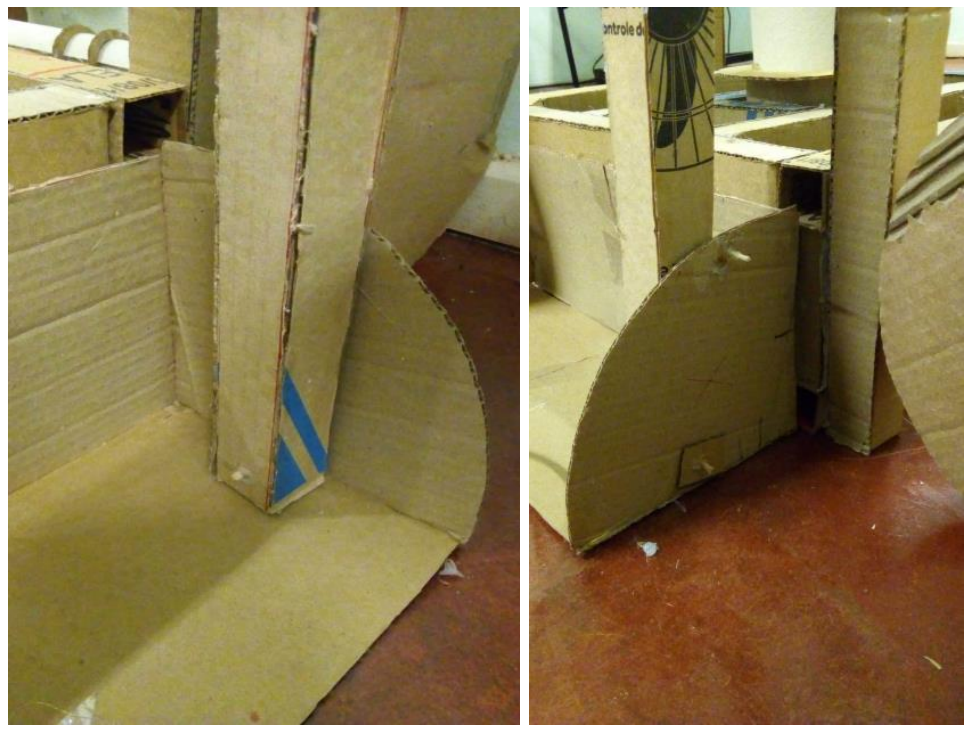

FIGURA 11 - Trava desenvolvida no modelo de papelão. Fonte: Autores (2019).

Por último, houveram questionamentos acerca da movimentação das rodas, ilustradas na Figura 12 , já que não puderam ser testadas no seu funcionamento completo.

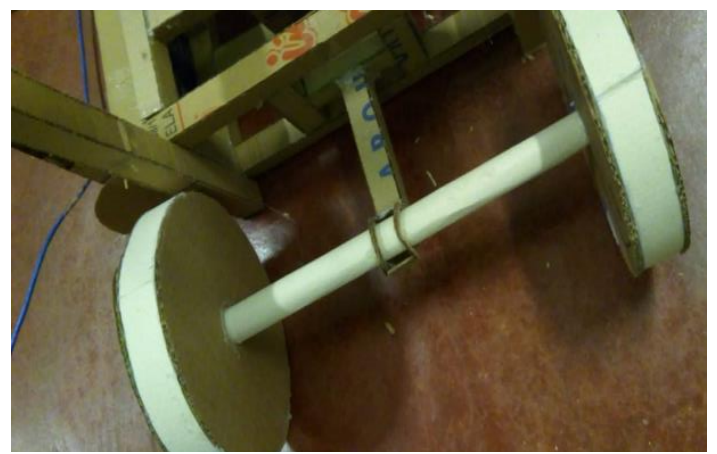

FIGURA 12 - Eixo e rodas do modelo. Fonte: Autores (2019).

Ficaram dúvidas pendentes sobre como seriam realizados seus movimentos laterais e se elas iriam favorecer o transporte do equipamento de forma fluida, considerando a irregularidades da superfície onde será utilizada.

\section{CONCLUSÃO}

Como exposto, as considerações feitas a partir do modelo desenvolvido geraram um conjunto de aspectos que precisam ser modificados para aperfeiçoamento do protótipo final. Esses pontos só foram percebidos com a materialização da alternativa que foi esboçada pela equipe, utilizando um modelo físico. Desse modo, percebe-se a importância de elaborar 
protótipos durante o processo de desenvolvimento de produtos, visando analisar erros e possibilitar melhorias.

O projeto encontra-se em fase de teste com o usuário, por isso, ainda pretende-se coletar e analisar as perspectivas sobre a alternativa na visão dos envolvidos no seu uso futuro. Esses testes também irão validar ou eliminar proposições, gerando melhorias para o protótipo final.

\section{AGRADECIMENTOS}

Agradecemos à SETI-PR (Secretaria da Ciência, Tecnologia e Ensino Superior do Paraná) e do Programa USF (Universidade Sem Fronteiras) e Fundo Paraná pelo financiamento deste projeto de extensão. Agradecemos ao Centro de Equoterapia Marisa Tupan pela parceria com o projeto SIMOPE: Sistema de mobilidade para portadores de necessidades especiais aplicado às práticas de equoterapia.

\section{REFERÊNCIAS}

ASSOCIAÇÃO BRASILEIRA DE EQUOTERAPIA [homepage na Internet]. Brasília: ANDE - Brasil. Disponível em: <http://www.equoterapia.org.br/site/>. Acesso em: 24 Jan. 2019.

BAXTER, Mike. Projeto de Produto: guia prático para o design de novos produtos. $3^{\text {a }}$ edição. Blucher. São Paulo, 2011.

BOARETTO, Marcelo Dondelli et al. Equoterapy center at a glance for ergonomic activity: Epidemiological prolife versus therapeutical practices. 20th Congress Of International Ergnomics Association, Florence, v. 20 , n. 1, p.759-764, ago. 2018. Anual.

BROWN, Tim. Change by Design: how design thinking transforms organizations and inspires innovation. HarperCollins e-books, 2009. Disponível em <academia.edu/9480893/Change_by_Design> Acesso em 28 maio de 2019.

COLLINS, J. W. et al., "An evaluation of a "best practices" musculoskeletal injury prevention program in nursing homes". Injury Prevention, 10, 4, 206-211. 2004.

LESSICK, M. et al. Horseback Riding: Exploring This Alternative Therapy for Women With Desabilities. AWHONN Lifelines, v. 8, n. 1, p. 46-53, 2004.

LÉVEILlÉ, A.; ROCHETTE, A.; MAINVILLE, C. Perceived risks and benefits of hippotherapy among parents of children currently engaged in or waiting for hippotherapy : A pilot study. Physiotherapy Theory and Practice, v. 33, n. 4, p. 269-277, 2017.

LOBACH, Bernd. Design Industrial: bases para a configuração dos produtos industriais. Editora Blucher. São Paulo, 2001.

LUZ, Maria de Lourdes Santiago; BOARETTO, Marcelo Dondelli; RODRIGUES, Jullia Maria Zullim. O trabalho em um Centro de Equoterapia sob a compreensão da ergonomia da atividade. [s.l.], v. 1, n. 37, p.1-19, 15 nov. 
2017. Anual. ENEGEP 2017 - Encontro Nacional de Engenharia de Produção. http://dx.doi.org/10.14488/enegep2017_tn_sto_241_397_34518.

MUNARI, Bruno. Das coisas nascem coisas. Martins Fontes. 3. Ed. São Paulo, 2015.

PAHL, G et al. Engineering Design: A systematic Approach. 3rd ed. Springer. London, UK.

PALHAIS, Catarina Bela Cardoso. Prototipagem: Uma abordagem ao processo de desenvolvimento de um produto. Universidade de Lisboa Faculdade de Belas-Artes. Mestrado em Design de Equipamento. Especialização em Design de Produto. $\quad$ Lisboa, $2015 . \quad$ Disponível <http://repositorio.ul.pt/bitstream/10451/29163/2/ULFBA_TES_942.pdf> Acesso em 28 de maio 2019.

PAVÃO, Luna Castro. “O que é que cavalo sabe': Um estudo antropológico sobre o vínculo animal- humano na equoterapia". 260p. Dissertação (Mestrado) - Centro de Educação e Ciências Humanas, Universidade Federal de São Carlos, São Carlos, 2015.

PAZMINO, Ana Veronica. Como Se Cria: 40 métodos para design de produtos. Blucher. São Paulo, 2013.

ROZENFELD, H. et al. Gestão de desenvolvimento de produtos: uma referência para a melhoria do processo. São Paulo: Saraiva, 2006. 